\title{
Desarrollo de la lengua materna Incidencia del género con una visión pragmática
}

Development of the mother tongue: Incidence of gender with a pragmatic

vision

(c) $\frac{i \text { (i) (2) }}{\mathrm{BY} N \mathrm{NA}}$
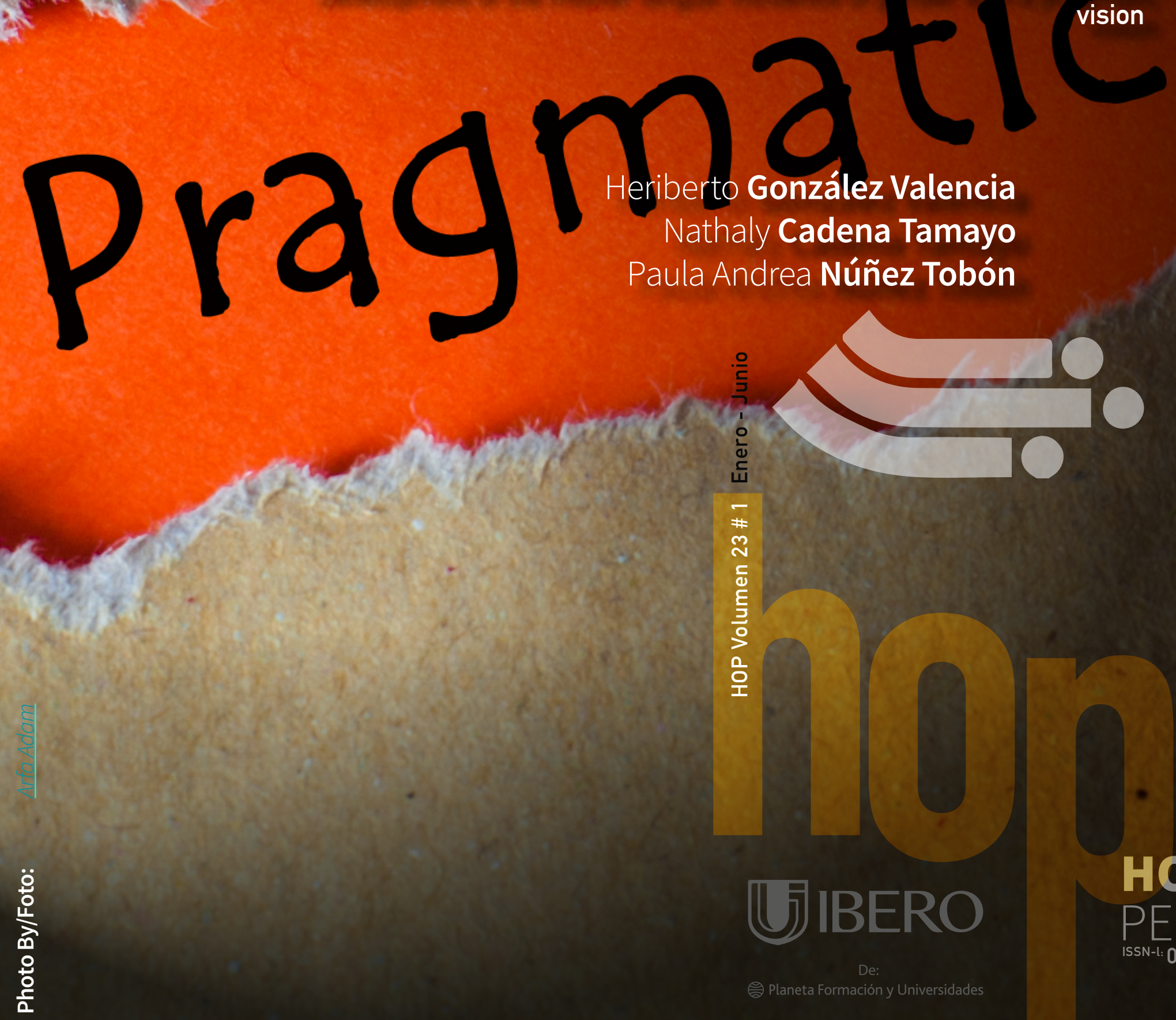

Heriberto González Valencia

Nathaly Cadena Tamayo

Paula Andrea Núñez Tobón

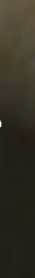


ID:

10.33881/0123-8264.hop.23104

Title: $\quad$ Development of the mother tongue: Incidence of gender with a pragmatic vision

Título: $\quad$ Desarrollo de la lengua materna: Incidencia del género con una visión pragmática

Author (s) / Autor (es):

González Valencia, Cadena Tamayo, \& Núñez Tobón

\section{Keywords / Palabras Clave:}

[en]: Pragmatic components; gender; sociocultural context; pragmatics; mother tongue.

[es]: $\quad$ Componentes pragmáticos; género; contexto sociocultural; pragmática; lengua materna

\section{Submited: 2021-03-23}

Acepted: 2021-03-29

\section{Resumen}

La investigación analizó por medio de diferentes actividades los diversos componentes pragmáticos en el habla espontánea de un niño y una niña, teniendo en cuenta principalmente las variables

del desarrollo del habla conversacional y los conceptos para su análisis. El objetivo principal se planteó en verificar si existe incidencia en el género en el desarrollo del lenguaje de un niño y una niña en la edad de los 3 años con un enfoque pragmático. Se realizó una investigación de tipo

cualitativa descriptiva, utilizando un modelo de evaluación. Se describen las actividades propuestas y realizadas individualmente con un seguimiento estricto de los investigadores. El contexto está enmarcado en situaciones reales y de confianza para los participantes. Los resultados muestran que el contexto es uno de los factores influyentes en el argumento final, pero la incidencia del género no muestra una diferencia significativa.

La participación del niño y la niña durante una actividad puede variar dependiendo del contexto y de la cercanía con los interlocutores. Se evidenció la influencia del contexto social; se deduce que no es el género el que incide en el desarrollo del componente pragmático en situaciones de habla espontánea.

\section{Abstract}

The research analyzed through different activities the various pragmatic components in the spontaneous speech of a boy and a girl, considering mainly the variables of the development of conversational speech and the concepts for their analysis. The main objective was established to verify if there is an impact on gender in the language development of a boy and a girl at the age of 3 years old with a pragmatic approach. A descriptive qualitative research was carried out, using an evaluation model. The activities proposed and carried out individually are described with strict monitoring by the researchers. The context is framed in real and trustful situations for the participants. The results show that the context

is one of the influencing factors in the final argument, but the incidence of gender does not show a significant difference. The participation of the boy and the girl during an activity can vary depending on the context and the closeness with

the interlocutors. In the case of this research, the influence of the social context was evident; it follows that it is not gender that influences the development of the pragmatic component in situations of spontaneous speech.

\section{Citar como:}

González Valencia, H., Cadena Tamayo, N., \& Núñez Tobón, P. A. (2021). Desarrollo de la lengua materna: Incidencia del género con una visión pragmática. Horizontes Pedagógicos , 23 (1), 3547. Obtenido de: https://horizontespedagogicos.ibero.edu.co/article/view/2101

\section{Heriberto González Valencia}

ORCID:

0000-0001-9103-2152

\section{Source I Filiacion}

Institución Universitaria Escuela Nacional del Deporte (IUEND)

\section{BIO:}

Doctor en Humanidades Artes y Educación de la Universidad Castilla La Mancha, España. Maestría Educación Superior. Especialización en Enseñanza en Educación Superior. Licenciatura en Lenguas Extranjeras.

\section{City | Ciudad:}

Bogotá DC [CO]

e-mail:

hery77@hotmail.com

\section{Lic Nathaly Cadena Tamayo}

ORCID: $\quad$ 0000-0001-7815-5369

BIO:

Licenciada en Lenguas Extranjeras

City I Ciudad:

Cali $[\mathrm{CO}]$

e-mail:

nathaly.cadena@correounivalle.edu.co

\section{Lic Paula Andrea Núñez Tobón}

ORCID: $\quad$ 0000-0002-8071-8308

BIO:

Licenciada en Lenguas Extranjeras

City I Ciudad:

Cali [CO]

e-mail:

pandrea170988@gmail.com 


\section{Desarrollo de la lengua materna Incidencia del género con una visión pragmática}

Development of the mother tongue: Incidence of gender with a pragmatic vision Heriberto González Valencia

Nathaly Cadena Tamayo Paula Andrea Núñez Tobón

\section{Introducción}

Diversos estudios en la década de los ochenta contribuyeron a la formación del concepto de desarrollo del habla en los niños, intentando comprender el proceso cognitivo infantil y el desarrollo en relación con el aprendizaje de la lengua (Borzone, silva y Plana 2011). Es a partir de los estudios realizados en esa época que se conoce que los niños comienzan a tener representaciones mentales desde sus primeros meses de vida. Esto implica que los niños desde temprana edad empiezan a desarrollar habilidades propias del habla. No obstante, es a partir de los 3 años que se observa el uso de un lenguaje organizado y una independencia en sus construcciones gramaticales. Fernández (2019) menciono que la eficacia comunicativa significa lograr un determinado propósito. Por otro lado, Peralta (2000) planteó que a los tres años el desarrollo pragmático infantil se hace más sofisticado y aumenta el lenguaje funcional, mientras que a la par desaparece el lenguaje egocéntrico y la ecolalia.

El enfoque pragmático ha supuesto una importante contribución al estudio de la adquisición del lenguajey durante lasúltimas décadas lasinvestigaciones pragmáticas han estado enascenso. Diversos autores a nivel internacional han realizado estudios direccionados al desarrollo del componente pragmático, mostrando cómo los niños desde temprana edad adquieren el conocimiento necesario para tener conversaciones eficientes y apropiadas. Adicionalmente, la incidencia del género dentro del desarrollo del lenguaje infantil ha sido una variable en distintas investigaciones tratando de evidenciar las diferencias en el desarrollo del habla dependiendo del sexo. En diferentes estudios se han obtenido resultados que muestran algunas variaciones en el desarrollo del lenguaje. Erikson et al. (2012) demostraron en su investigación con 13.873 niños europeos que las niñas, de manera leve, desarrollan más tempranamente gestos comunicativos en el vocabulario productivo y en palabras que se combinan. Estos autores exponen la teoría de la socialización, según la cual la influencia en el ambiente que tienen los niños desde temprana edad influye en la adquisición del lenguaje; en otras palabras, desde los juguetes hasta la forma en que se les habla a los niños marcan una diferencia en el desarrollo del lenguaje y así como en las habilidades conversacionales (Erikson et al., 2012). 


\section{Desarrollo de la lengua materna: Incidencia del género con una visión pragmática}

Es a partir de estos planteamientos que surge la idea de analizar por medio de diferentes actividades los diversos componentes pragmáticos en el habla espontánea de un niño y una niña de tres años y medio. Para esto se han tenido en cuenta principalmente las variables del desarrollo del habla conversacional y los conceptos para sus análisis planteados por Acuña y Sentis (2004); a saber: la toma de turno, mantener el tópico de la conversación, la comunicación de las referencias, la adaptación del habla al oyente y la realización de peticiones que un interlocutor debe tener para alcanzar una comunicación efectiva.

Con base en lo anterior se realiza un análisis de la incidencia que puede tener el género en el desarrollo del habla conversacional desde una visión pragmática, teniendo en cuenta que la influencia del género no es un concepto que se ha descartado en los estudios del desarrollo del lenguaje y que existen varias investigaciones donde se muestra que los niños desde temprana edad desarrollan habilidades diferentes en el lenguaje.

La presente investigación, entonces, se basa en la incidencia del género en el desarrollo de la adquisición de la lengua materna desde una mirada a la pragmática por medio de la interacción espontánea, en un niño y una niña de 3 años que comparten aspectos socioeconómicos, culturales y académicos. Rodríguez y Yepez (2017) argumentaron que el contexto social y familiar son factores determinantes para la adquisición del lenguaje. Por otro lado, Coloma, Pavez, Maggiolo, y Peñaloza (2010) mencionaron que estudiar el desarrollo fonológico es una tarea que requiere considerar las discrepancias entre las producciones lingüísticas de los adultos y las de los niños. Teniendo en cuenta que el ingreso a la etapa lingüística del niño es progresiva (Arconada, 2012). La interacción de los niños en el contexto con las investigadoras y su avance en un ritmo estable y progresivo permitió un desarrollo adecuado a su edad y capacidad de compresión de las actividades.

\section{La pragmática}

La Pragmática es conocida como la rama de la lingüística que estudia el lenguaje teniendo en cuenta su función más que su estructura. Se le concibe como el estudio del uso del lenguaje en un contexto interaccional real por parte de interlocutores reales (hablantes y oyentes) (Acuña y Sentis, 2004). La pragmática se diferenció desde los años 80 por pasar de una visión estructural hacia posiciones funcionales en las investigaciones sobre los procesos de aprendizaje lingüístico en las primeras etapas del desarrollo del lenguaje. Es así como la pragmática enfoca sus estudios en el uso del lenguaje por parte de los hablantes y el contexto donde se desarrolla la comunicación. Este enfoque ha supuesto una importante contribución al estudio de la adquisición del lenguaje (Verde, 2015). Granato y Rigatuso (2020) propusieron que los hablantes interactúan sobre la base de dos criterios básicos: un criterio de informatividad, que supone la elección de la mejor expresión de lo que se quiere decir, y un criterio de comprensibilidad que contempla específicamente la inteligibilidad por parte del oyente. Por otro lado, Varela, Varela y Medina (2017) mencionaron que la pragmática fue pensada para analizar los actos de habla, la conversación, la comunicación y los usos del lenguaje.

Basado en lo anterior, Miller (1981) citado por Carmona (1985) plantea que la pragmática del lenguaje infantil se ha dirigido al análisis de las intenciones que tiene el hablante para comunicarse con el oyente, es decir, las razones por las que las personas hablan y se comunican con los otros. Aunque la pragmática se ha venido estudiando desde los 80, como se explicó anteriormente, Huamaní (2014) manifiesta que la definición de esta se comenzó a realizar a lo largo del siglo XX, y aún a la fecha existen discrepancias entre los autores para poder tener una única definición. Reyes (2018) menciono que la pragmática combina lo lingüístico con lo extralingüístico y con ello hace muchísimo más comprensible la forma en la que se produce la comunicación entre los seres humanos.

Los límites del estudio de la pragmática todavía están difusos, todavía no hay una teoría que unifique todos los criterios abordados por los distintos autores al tratar de explicar, estos criterios son bastantes heterogéneos (funcionalidad comunicativa, discurso, comunicación referencial, enunciados figurados, comunicación no verbal, implicaturas escalares, inferencias pragmáticas, etc.) (Huamaní, 2014, p.01).

A partir de esa misma idea se conciben dos definiciones o divisiones conceptuales de la pragmática: se puede ver como un componente del lenguaje o como el núcleo que determina y organiza los aspectos estructurales del lenguaje (Huamaní, 2014). Sin embargo, estos dos conceptos que plantea Huamaní se han unificado, ya que la pragmática es un componente del lenguaje que estudia los aspectos que estructuran el lenguaje al momento de las interacciones, analizando la intencionalidad del hablante.

Retomando la pragmática como el análisis de las intenciones que tiene el hablante para comunicarse, Acuña y Sentis (2004) concuerdan con esta definición de pragmática, ya que ellos miran el concepto desde un punto de vista social, en el cual el lenguaje se desarrolla por medio de la interacción social, teniendo como finalidad la producción de enunciados con una intencionalidad definida, la cual consiste en realizar actos lingüísticos que dan como resultado conductas específicas por parte del interlocutor. Crespo et al. (2016) argumentaron que el uso funcional-social del lenguaje vehicula conocimientos compartidos, propósitos, sentimientos, creencias y, en definitiva, inferencias más allá del significado literal.

Para complementar esta definición se puede citar a Bertuccelli (1996), quien define la pragmática como un campo que estudia la manera en que funciona el lenguaje visto desde los contextos sociales, situacionales y comunicativos y en el cual se ocupan una generalidad de normas que organizan el uso intencional del lenguaje. Según Soncco (2017) el desarrollo del lenguaje implica que el niño manifieste interés por el contacto social con los demás y que se involucre con ellos.

Teniendo en cuenta los anteriores planteamientos sobre la definición de la pragmática y su importancia en las investigaciones, vale la pena hablar sobre los contextos, ya que es el contexto el que puede determinar el modo y el uso del lenguaje en una conversación. Según la RAE, el contexto se define como "Entorno lingüístico del cual depende el sentido y el valor de una palabra, frase o fragmento considerados." Teniendo en cuenta esta definición, se puede decir que el contexto hace referencia a las características de las circunstancias en las cuales se produce una conversación o interacción entre dos o más personas, las cuales, según los estudios pragmáticos, son circunstancias relevantes para la interpretación de las intenciones del hablante. Desde este punto de vista, se percibe como muy influyente la relación de los niños en sus entornos familiares, académicos y sociales para el desarrollo de su lenguaje.

Es así como se puede concluir que el concepto de pragmática no tiene una única percepción. No obstante, diversos autores hacen hincapié en el análisis del uso del lenguaje teniendo en cuenta las razones o las intenciones que tiene el hablante y observando el contexto en el que sucede la conversación. 


\section{Diseño de la investigación.}

La metodología implementada en el presente estudio comparativo del desarrollo del componente pragmático en dos niños de ambos sexos. La investigación es de tipo cualitativa descriptiva, de acuerdo con Taylor y Bogdan (1986) la investigación cualitativa es aquella que produce datos descriptivos. LeCompte (1995) argumento que esta se entiende como una categoría de diseños de investigación que extraen descripciones a partir de observaciones. La investigación cualitativa se caracteriza por desplazarse al contexto natural donde acontecen las experiencias, donde viven las personas y donde puede recoger las situaciones, es decir, el investigador se centra en recoger todos los momentos de las situaciones vividas por los participantes dentro de su emplazamiento natural (Cotán, 2017). Se utilizó el modelo de evaluación planteado por Alemán et al. (2006) en su Manual de la Evaluación de la Comunicación y el Lenguaje.

\section{Población y Muestra}

La integración de los participantes con las características particulares permitirá responder los objetivos planteados, ya que, con una apropiada selección, se podrá disponer de resultados confiables, dichos resultados puedan ser extrapolados a otras poblaciones similares (Arias, Villasís y Novales, 2016). Los participantes de este estudio fueron un niño y una niña colombianos. Ellos iniciaron con una edad de 42 meses y 44 meses y finalizaron con 46 meses y 48 meses, respectivamente. Ambos participantes asistían a jardines infantiles de estrato socioeconómico medio-bajo y evidenciaban un desarrollo lingüístico apropiado para su edad. Esto último se constató en el informe escolar de cada participante y con una entrevista con los padres de familia se corroboró además su historial médico y pedagógico, evidenciando que ninguno de los dos niños asistía a terapias de lenguaje, lo que evidenció que sus procesos académicos y sociales eran adecuados.

Ambos participantes pertenecen a una familia conformada por ambos padres biológicos y un hermano del sexo opuesto. Botana, Peralbo y García (2017) enfatizaron el rol crucial y formativo que desempeñan las experiencias tempranas, especialmente te durante los dos primeros años de vida, en el desarrollo social y emocional del ser humano; adicional a esto, los participantes ingresaron a la vida académica a la edad de 2 años y en el momento de la investigación pertenecían al mismo grado de escolaridad. Otzen y Manterola (2017) propusieron que la representatividad de una muestra permite extrapolary por ende generalizar los resultados observados en ésta.

\section{Instrumentos de Recolección de Datos}

Una investigación es científicamente válida al estar sustentada en información verificable, por lo tanto, es imprescindible realizar un proceso de recolección de datos en forma planificada y teniendo claros objetivos sobre el nivel y profundidad de la información a recolectar (Torres, Salazar y Paz, 2019). El instrumento de recolección de datos fueron tres actividades interactivas, las cuales son denominadas: Caja de Juguetes, Sigue la Historia y Rompecabezas. Para la recolección de los datos se utilizaron videos y audios que permitieron generar el corpus. 2 de ellas eran interactivas tomadas del autor Gamazo (2016), mientras que la 3 fue planteada tanto en Gamazo (2016) como en Bonilla-Solorzano (2016). Esta última actividad es controlada, pero permite la interacción espontánea. El instrumento es utilizado para recolectar información clara y precisa, para hacer el análisis de datos, depende de la investigación el instrumento a utilizar (Urbano, 2016).

\section{Resultados}

Como instrumento de evaluación y de recolección de datos se recurrió a tres actividades planteadas por Gamazo (2016):
Caja de Juguetes
Sigue la Historia
Rompecabezas

\section{CAJA DE JUGUETES}

\section{Seguir el Tema de Conversación}

Como se observa en la gráfica No. 01, la conversación fluyó de manera permanente y no se encontró una diferencia significativa en los aportes que los niños hicieron.

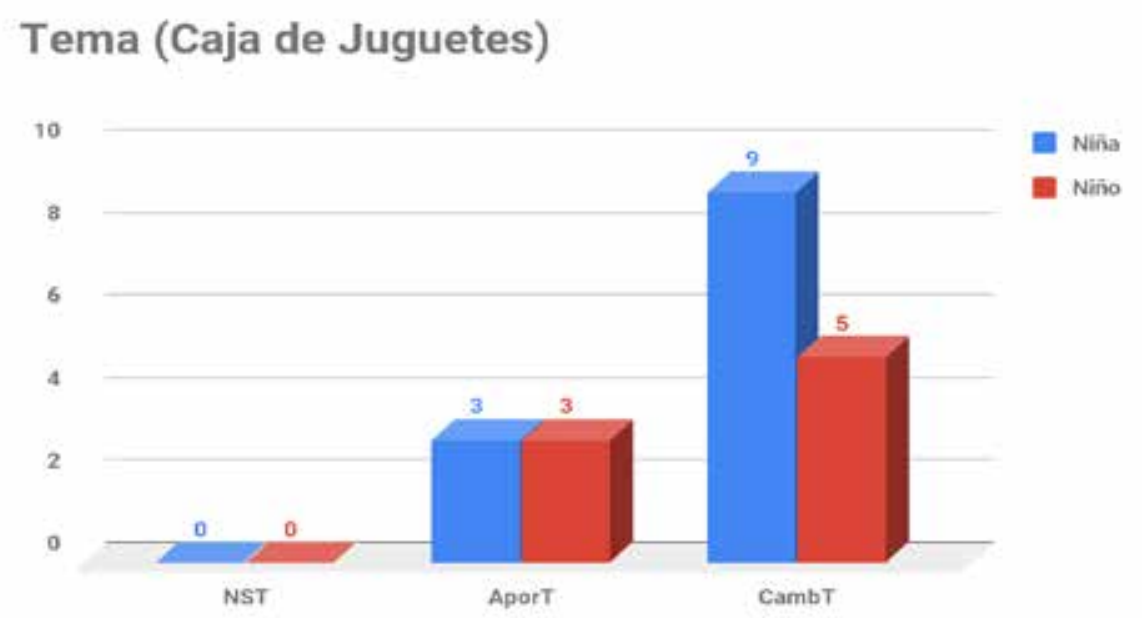

Gráfico 01: Tema en la Caja de Juguetes.

En el ítem Aporte al Tema (AportT) se encontró que ambos participantes hicieron la misma cantidad de aportes en la conversación en sus respectivos videos. En el tercer ítem, Cambia el Tema (CambT), se puede observar que sí se encuentra una pequeña diferencia entre los niños y sus intervenciones. En los videos se puede ver una diferencia en los comportamientos de los participantes. Por un lado, en la actividad con la niña, la participante interactúa con los juguetes. Por otro lado, en la actividad realizada con el niño, no se observaron juegos o interacción con los juguetes. En la Caja de Juguetes se tomó como cambio de tema cuando los participantes hablaban de un objeto diferente al que los investigadores estaban haciendo referencia. En varias ocasiones se puede visualizar que ambos niños intentan escoger el juguete de su preferencia, intentando así cambiar el rumbo de la conversación. En los dos ejemplos sobre CambT podemos observar que ambos niños toman un juguete de la caja mientras los investigadores están tratando de hablar sobre un objeto diferente. 


\section{Desarrollo de la lengua materna: Incidencia del género con una visión pragmática}

\section{Respetar los Turnos de Palabra}

Como se muestra en la gráfica 02, el niño fue el único quien se mostró activo para los dos ítems, que son: No respeta el turno (NRT), y Solapa el turno esperando un tiempo (AaT). Para esta actividad ninguno de los niños respondió al tiempo cuando los investigadores realizaron alguna intervención, por lo cual no se hablará del ítem Responden al tiempo (RalT).

\section{Turnos (Caja de Juguetes)}

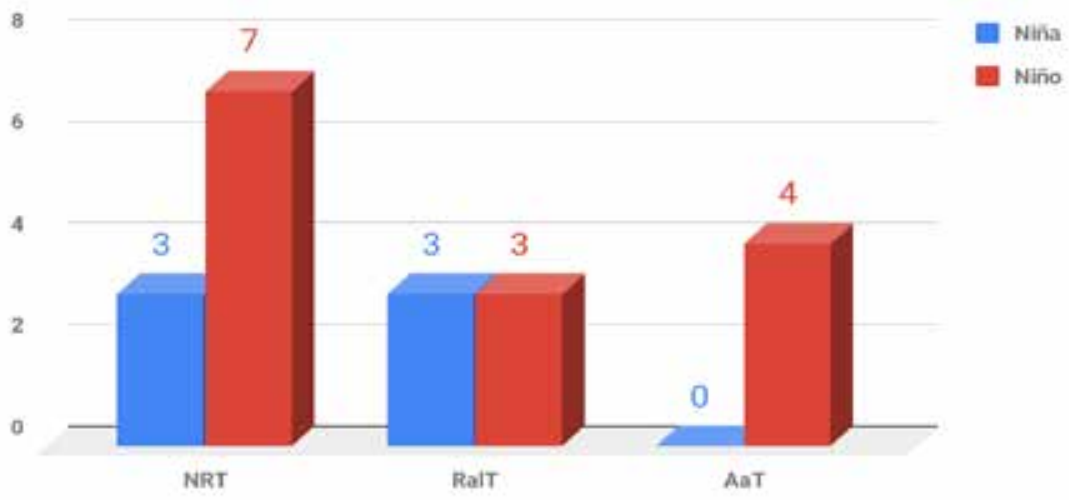

Gráfico 02: Toma de Turnos Caja de Juguetes.

En el primer ítem, NRT, se pudo ver que el niño quita el turno con mayor frecuencia que la niña. En el segundo ítem RalT los participantes (niño y niña) responden al tiempo en tres oportunidades.

\section{Ser Activo en la Conversación}

Este objetivo se refiere a la participación y para esto se utilizaron dos ítems: Es Activo (eA) y no es activo (NeA). Respecto a la participación, se puede observar que ambos niños fueron activos, interesándose por responder y hablar sobre los juguetes que les mostraban los investigadores. Sin embargo, se puede observar que el participante masculino tuvo un mayor número de intervenciones en la actividad caja de juguetes.

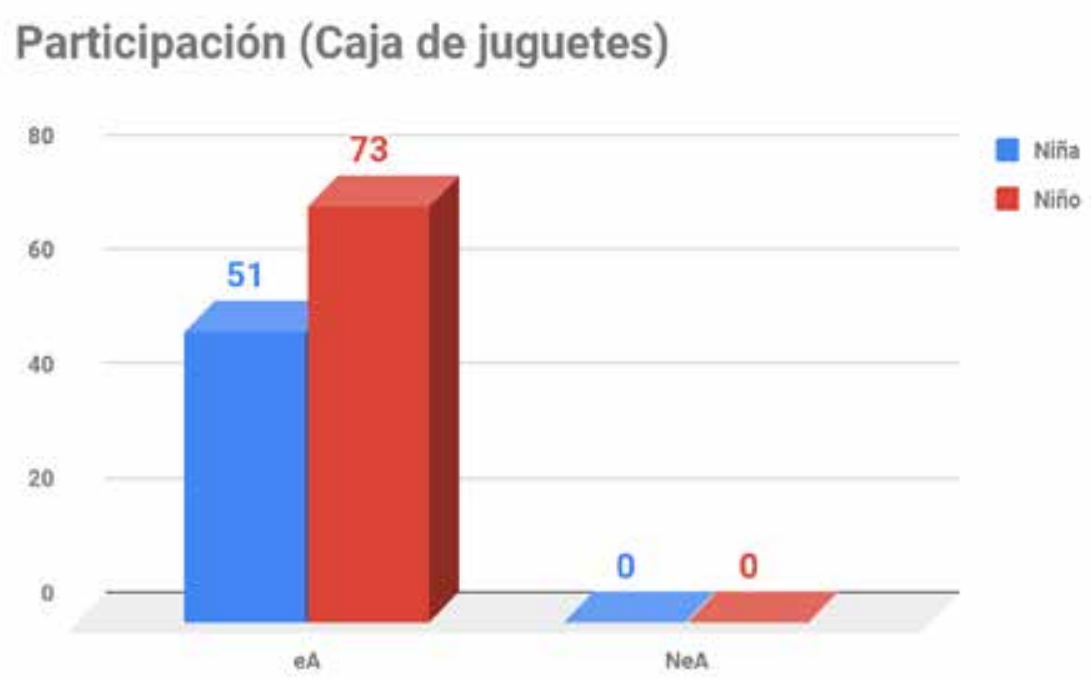

Gráfico 03: Participación en la Caja de Juguetes.

En el primer ítem, eA, es donde se codificó cada participación de los niños, sin tener en cuenta si era verbal o no verbal, ya que cada intervención de los integrantes es importante para el desarrollo de la actividad.

\section{Uso gramatical de las palabras}

En este objetivo se destacaron cinco ítems analizando diferentes pronombres, los cuales son: Pronombres Personales Tónicos (PpT), Pro- nombres personales Átonos (PpA), Pronombres Demostrativos (PdD), Pronombres Posesivos (Ppose) y Pronombres Preposicionales (Ptp). Como se puede ver en la gráfica No. 04 hubo un uso continuo de los cinco ítems antes mencionados, sin embargo fue más frecuente en ambos participantes el uso del PdD.

\section{Uso de Pronombres (Caja de Juguetes)}

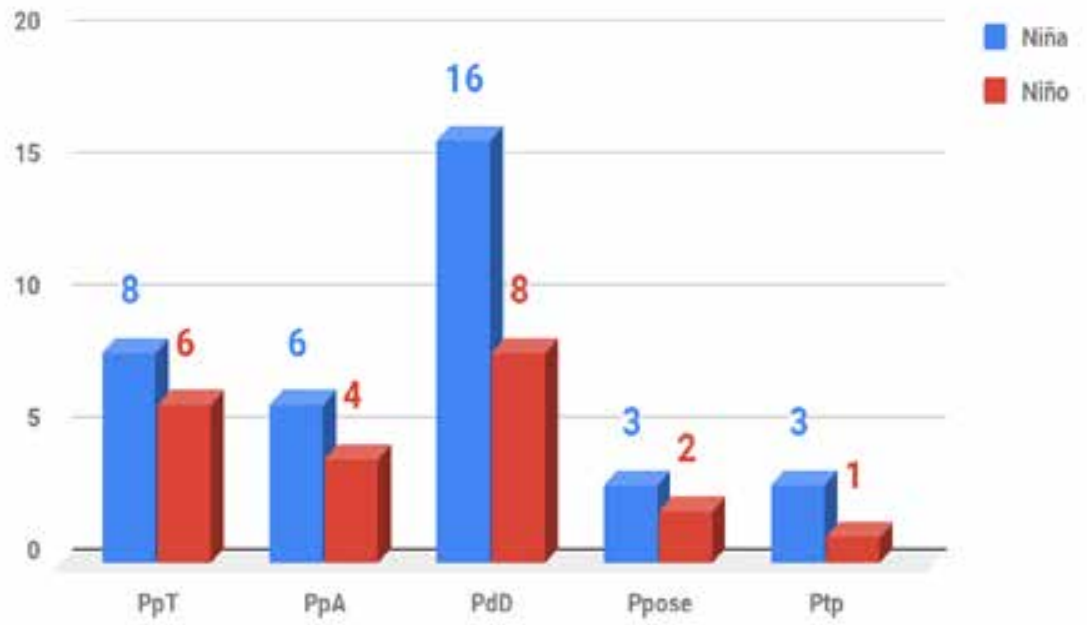

Gráfico 04: Pronombres en la Caja de Juguetes.

\section{Uso de adverbios}

El objetivo en este componente es evaluar la frecuencia de uso de los adverbios en los participantes. En este caso, los adverbios de Cantidad (AdvDCant) no fueron utilizados por los informantes como se puede ver en la gráfica No. 05. Por este motivo sólo se analizaron el Adverbio de lugar (AdvDPlace) y el Adverbio de modo (AdvDmodo), en los que los participantes tuvieron variaciones en la frecuencia como se puede observar en la siguiente gráfica.

\section{Uso de Adverbios (Caja de Juguetes)}

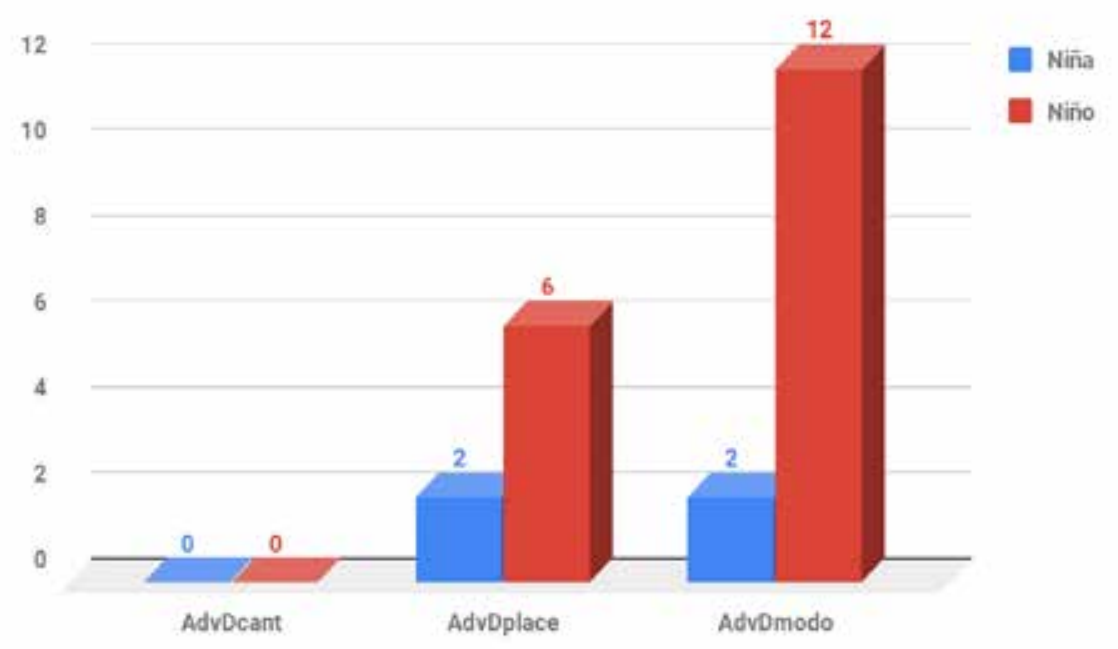

Gráfico 05: Adverbios en la Caja de Juguetes.

\section{Uso de nexos}

En este punto podemos observar que en la actividad Caja de Juguetes no se encontró evidencia del uso de los nexos ilativo (Nexoila), de Lugar (Nexoplace) y final (Nexoend); sin embargo, se dejan en la gráfica puesto que en las otras actividades sí se evidenciaron. En los seis nexos restantes que se observan en la Gráfica No. 06 se encontraron usos adecuados. 


\section{Uso de Nexos (Caja de Juguetes)}

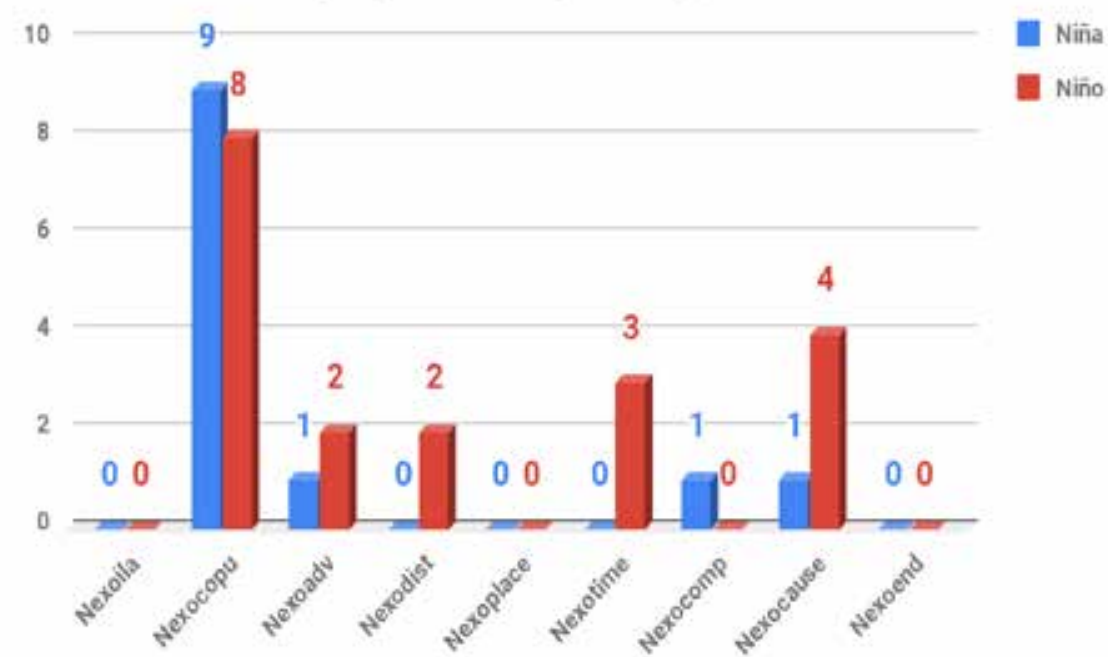

Gráfico 06: Nexos gramaticales en la Caja de Juguetes.

\section{SIGUE LA HISTORIA}

\section{Seguir el tema de conversación}

Se visualizaron tres ítems que permiten evaluar si los participantes pueden mantener el tema de una manera continua y prolongada. Los ítems son: No sigue el Tema de Conversación (NST), Aportes al Tema (AporT) y Cambia el Tema de Conversación (CambT). Como se puede observar en la siguiente gráfica, ambos niños mantienen el tema en la mayoría del tiempo en la actividad. Por este motivo, la gráfica No. 07 muestra que en el primer ítem ambos participantes tienen cero. En el ítem AporT se ve como ambos niños contribuyen de una manera espontánea para que la historia siga su curso. Para el tercer ítem, CambT, el gráfico muestra que la niña cambió el tema de conversación en tres ocasiones más que el niño.

\section{Tema (Sigue la Historia)}

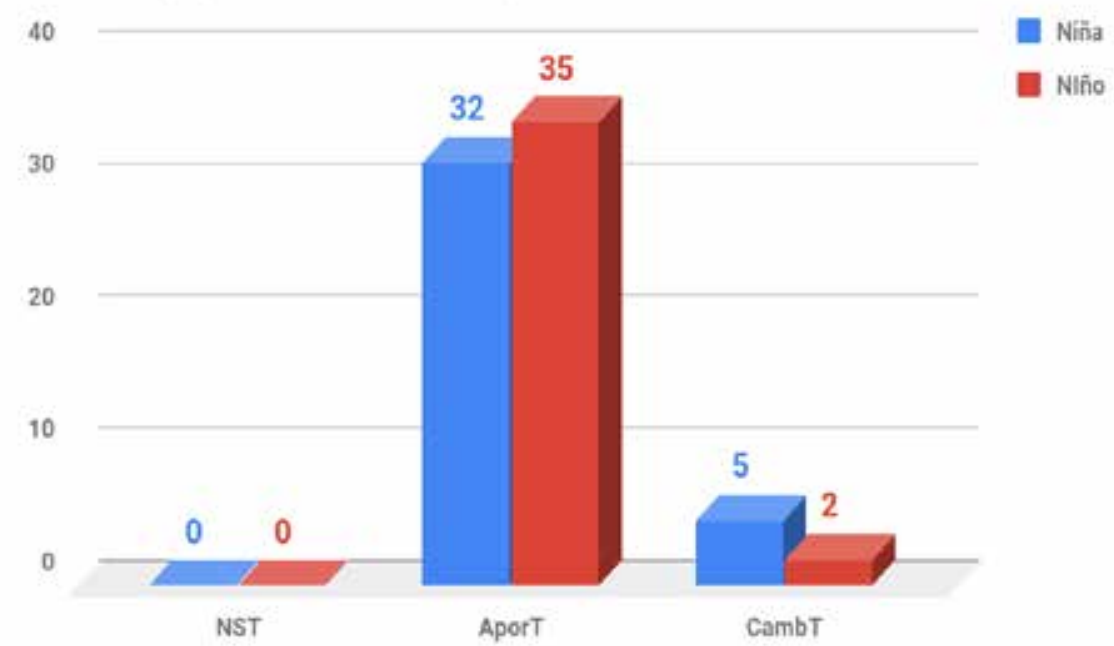

Gráfico 07: Tema de Conversación en Sigue la Historia.

\section{Respetar los turnos de palabra}

A continuación se muestra la gráfica cuyos datos muestran que el niño tuvo mayor actividad en los tres ítems, que son: No respeta el turno (NRT), Responden al mismo tiempo (RalT) y Solapa el turno esperando un tiempo (AaT). Como se puede ver en la gráfica No. 08, Turnos en Sigue la Historia, la participante niña no utilizó ninguno de los tres componentes de este objetivo, teniendo en cuenta que no se codificaron las veces que los participantes respetaban los turnos, sino únicamente aquellas en que no los respetaban, visualizándolo en los tres ítems nombrados previamente.

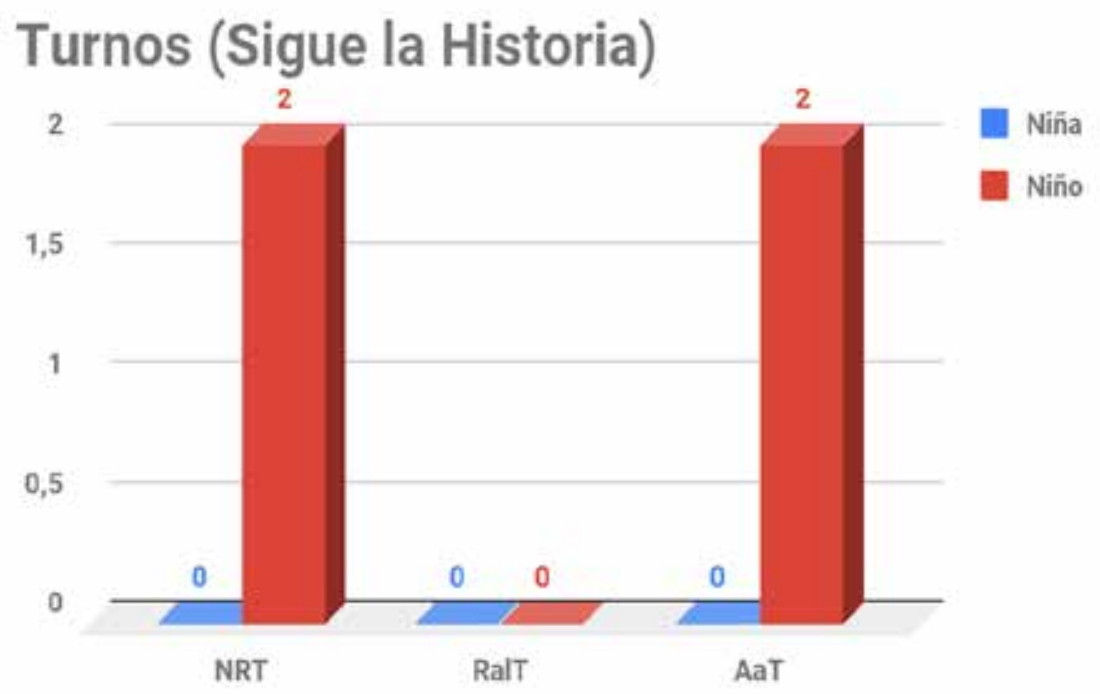

Gráfico 08. Toma de Turnos Sigue la Historia.

\section{Ser activo en la conversación}

Se priorizaron los siguientes ítems: Es Activo (eA) y no es activo (NeA). Por medio de la Gráfica No. 09 se puede ver que ambos niños participaron activamente, realizando aportes de acuerdo al tema para crear una historia, la cual estuvo guiada por los investigadores.

\section{Participación (Sigue la Historia)}

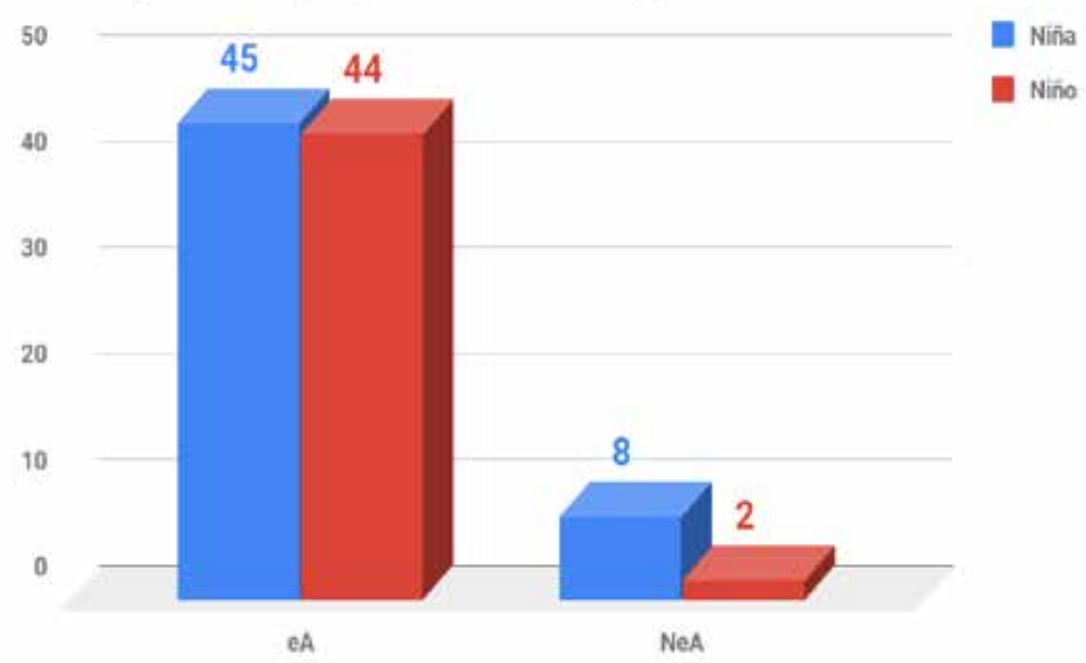

Gráfico 09: Participación en Sigue la Historia.

\section{Uso gramatical de las palabras}

Se analizaron las siguientes clases de pronombres: Pronombres Personales Tónicos (PpT), Pronombres personales Átonos (PpA), Pronombres Demostrativos (PdD), Pronombre Posesivos (Ppose) y los pronombres personales preposiciones (Ptp). Como se puede ver en la Gráfica No. 10 hubo un uso continuo de los cuatro ítems antes mencionados, exceptuando el Ppose el cual no fue utilizado por ninguno de los participantes para esta actividad. 


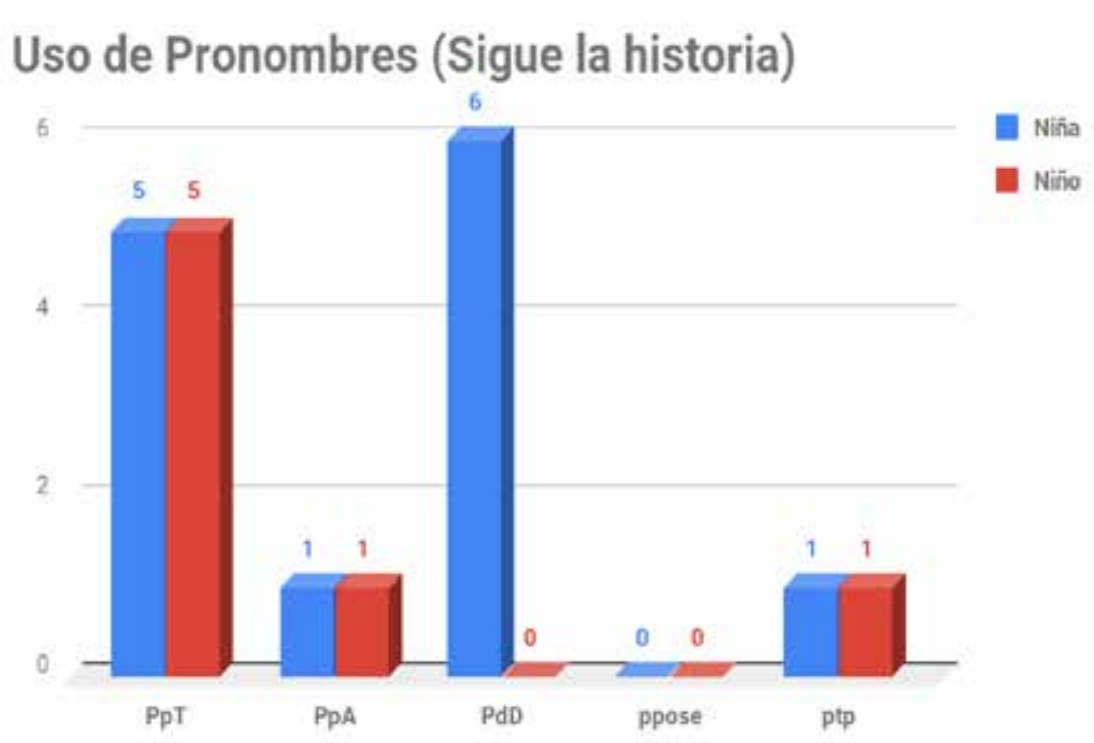

Gráfico 10: Pronombres en Sigue la Historia.

\section{Uso de adverbios}

Se analizó la utilización de tres tipos específicos de adverbios que se vieron reflejados en el corpus: los Adverbios de Cantidad (AdvDCant), los Adverbios de lugar (AdvDPlace) y los Adverbios de modo (AdvDmodo), según los datos que se muestran en la Gráfica No. 11, hubo una pequeña diferencia entre los participantes.

\section{Uso de Adverbios (Sigue la Historia)}

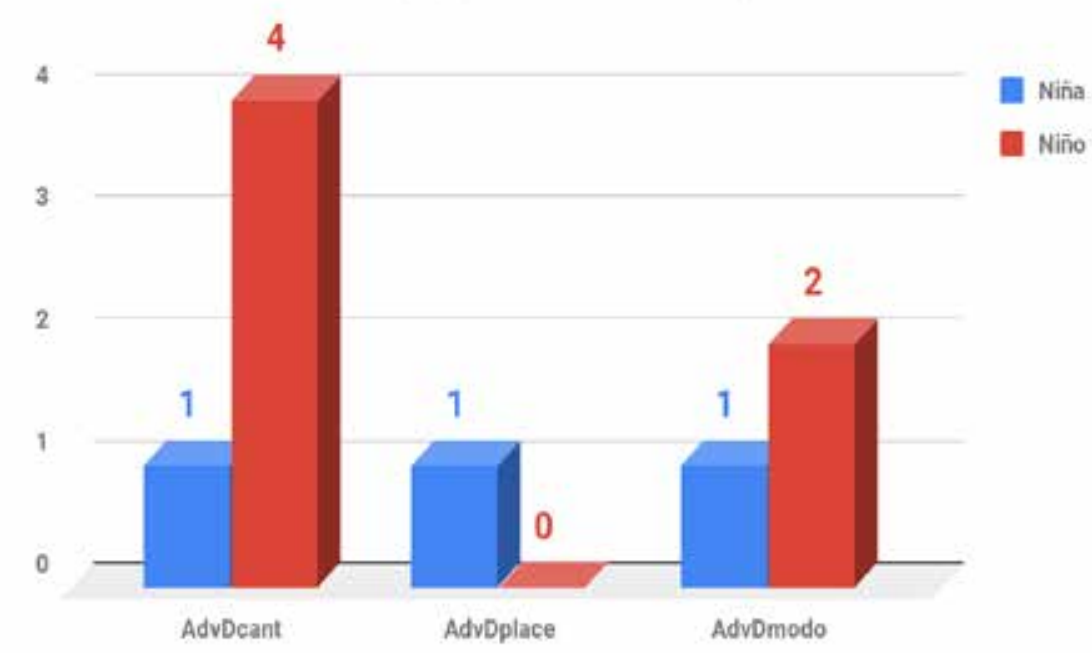

Gráfico 11: Adverbios en Sigue la Historia.

\section{Uso de nexos}

El último componente del uso gramatical es evaluar los nexos que los participantes usaron, estos están divididos en dos grandes grupos que son:

1. Los dos Nexos Coordinantes: nexos copulativos y adversativos.

2. Los siete Nexos Subordinantes: nexos ilativos, distributivos, de lugar, de tiempo, comparativos, causales y finales.

En el caso de la actividad "Sigue la Historia", los participantes usaron todos los nexos coordinantes, sin embargo en el caso de los nexos subordinantes únicamente hicieron uso de los nexos de causa.

\section{Nexos (Sigue la Historia)}

5

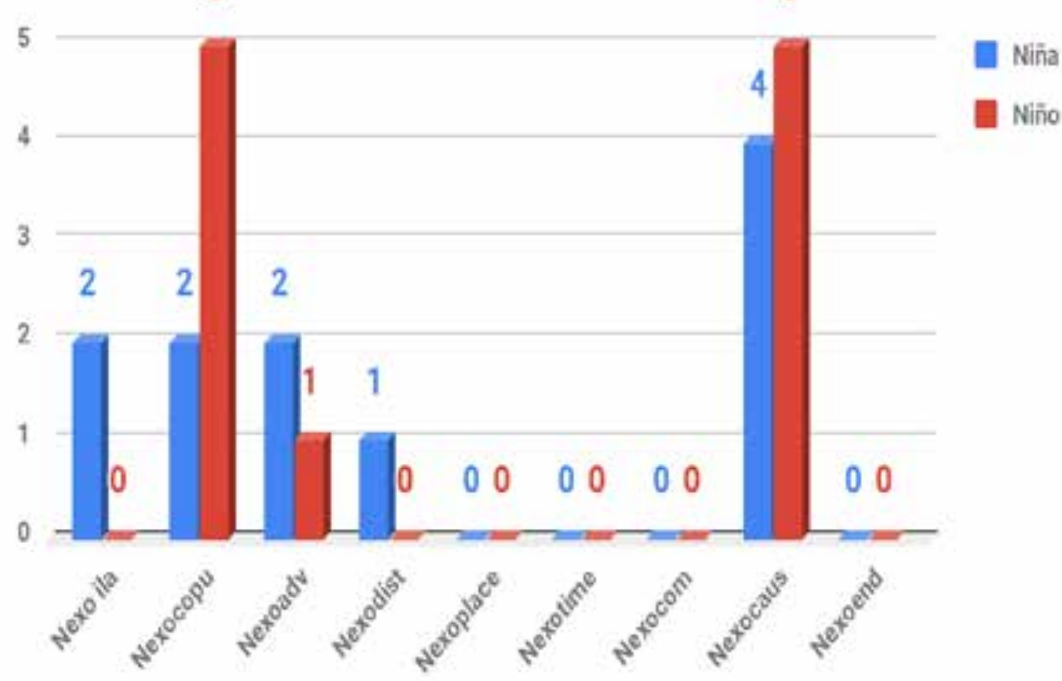

Gráfico 12: Nexos en Sigue la Historia.

\section{ROMPECABEZAS}

Como principal objetivo en la realización de esta actividad se pretende ver cómo los participantes interactúan cuando necesitan ayuda para realizar un rompecabezas. Por este motivo se escogió realizar la actividad de forma separada con cada niño. Con esto también se buscó poder visualizar los dos objetivos de los que no se encontraron datos en las primeras actividades, los cuales son: solicitar información (Sinfo) y Solicitar ayuda (Shelp), sin dejar de lado los otros cuatro objetivos que se han venido analizando durante todas las actividades.

\section{Seguir el tema de conversación}

Como se observa en la Gráfica No. 13, Tema de Conversación en el Rompecabezas, este fluyó de manera permanente y constante, tal y como se puede visualizar en el primer ítem, No sigue el Tema, el cual no tuvo incidencia para ninguno de los dos participantes. En esta actividad los participantes tuvieron diferentes modos de participación. Mientras que la niña hizo más cambios de tema, el niño tuvo más aportes al tema, pero ambos seguían la conversación fluidamente.

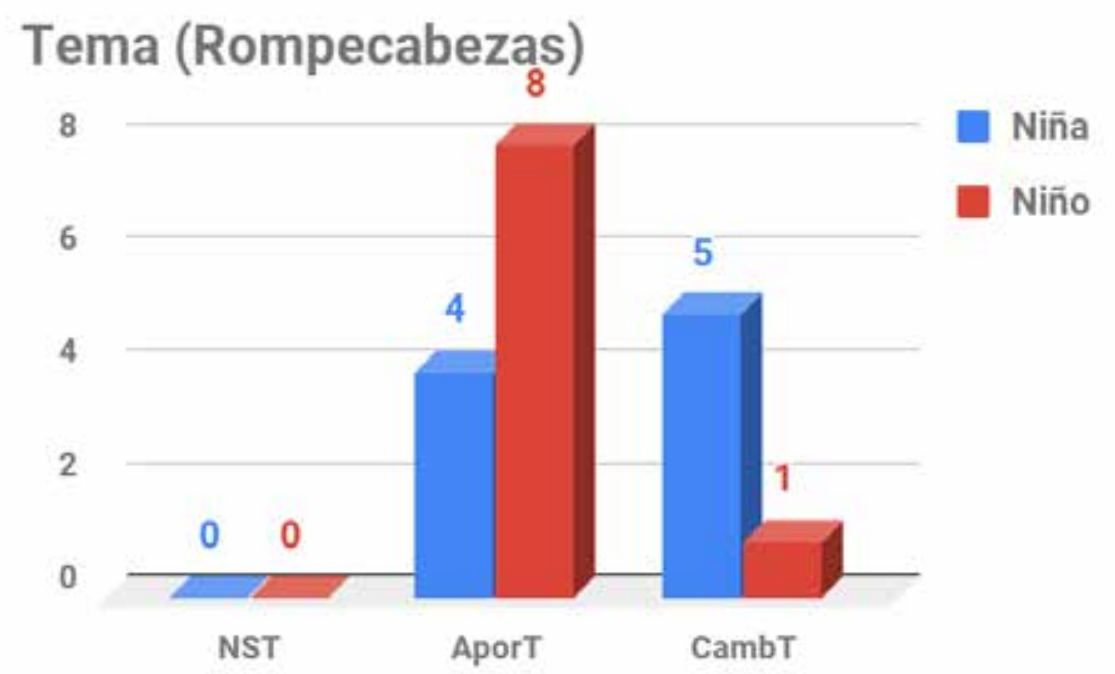

Gráfico 13: Tema de Conversación en el Rompecabezas.

En el segundo ítem, Aporte al Tema (AportT), se encontró que el niño tuvo el doble de aportes en comparación con niña. De igual manera, ambos participantes dieron aportes similares en su respectiva participación. 


\section{Respetar los turnos de palabra}

Podemos ver que para esta actividad denominada "Rompecabezas" ambos participantes respetaron los turnos de manera constante puesto que era una conversación de habla espontánea con un adulto y, como se ha mencionado antes, los participantes solo se atrevían a interrumpir los turnos de individuos de su misma edad, manteniendo así un respeto por aquellos quienes son una figura de autoridad.

\section{Turnos (Rompecabezas)}

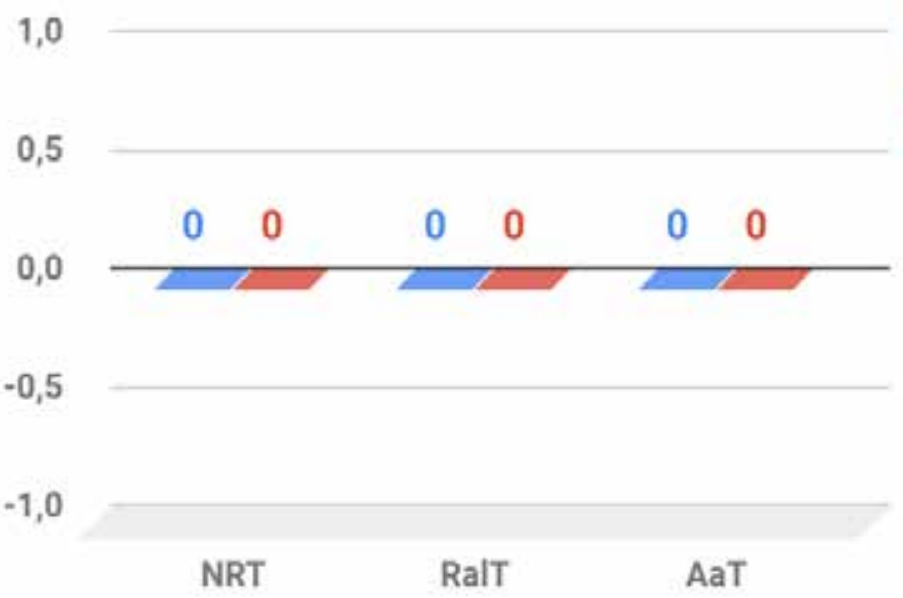

Gráfico 14: Toma de Turnos en el Rompecabezas.

\section{Ser activo en la comunicación}

En este objetivo, al igual que en las dos actividades anteriores, se tuvieron en cuenta los ítems: Es Activo (eA) y no es activo (NeA). En esta actividad ambos niños se mostraron motivados por participar, sin embargo, en la gráfica 15 vemos que el niño tuvo más intervenciones a comparación de la niña. Cabe destacar, no obstante, que ambos rompecabezas eran diferentes y que al niño le tomó 15 minutes armarlo mientras que a la niña 10.

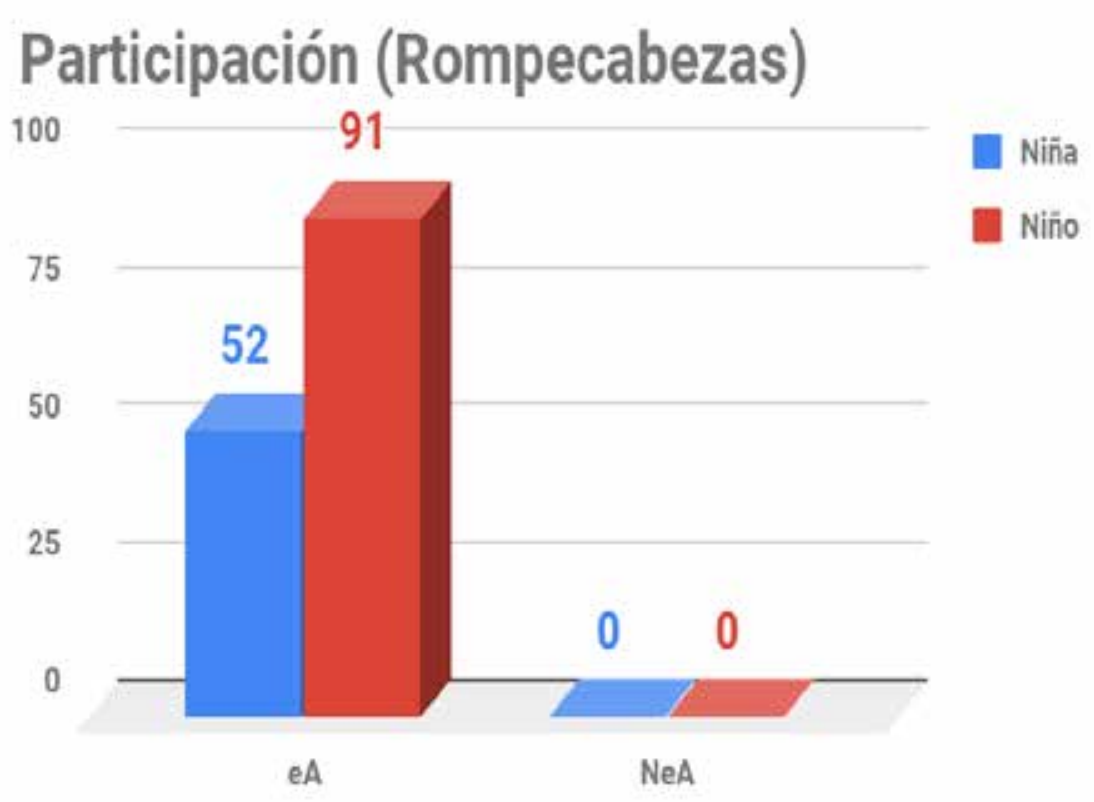

Gráfico 15: Participación en el Rompecabezas.

\section{Uso gramatical de las palabras Uso de pronombres}

Como se ha venido realizando en las anteriores actividades, el componente de los pronombres va a estar dividido en cinco ítems tal y como se observa en el gráfico 16. Los ítems son: Pronombres personales tónicos (PpT), pronombres personales átonos (PpA), pronombres demostrativos (PdD), pronombres posesivos (Ppose) y pronombres preposicionales (Ptp).

\section{Pronombres (Rompecabezas)}

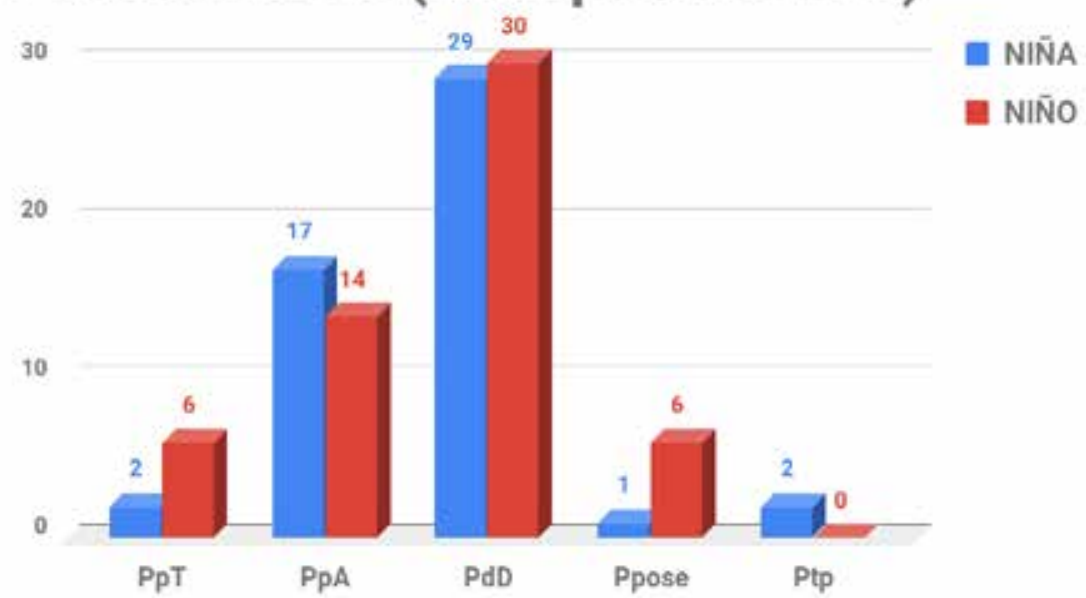

Gráfico 16: Pronombres en el Rompecabezas.

\section{Uso de adverbios}

El objetivo en este caso es evaluar la utilización de los adverbios. En esta investigación se observaron tres tipos de adverbios: adverbios de Cantidad (AdvDCant), adverbios de lugar (AdvDPlace) y adverbios de modo (AdvDmodo). En la actividad Rompecabezas se vio una mayor cantidad de adverbios de lugar que en las anteriores actividades, teniendo en cuenta que para el contexto de las intervenciones y de la actividad, era pertinente su uso frecuente.

\section{Adverbios (Rompecabezas)}

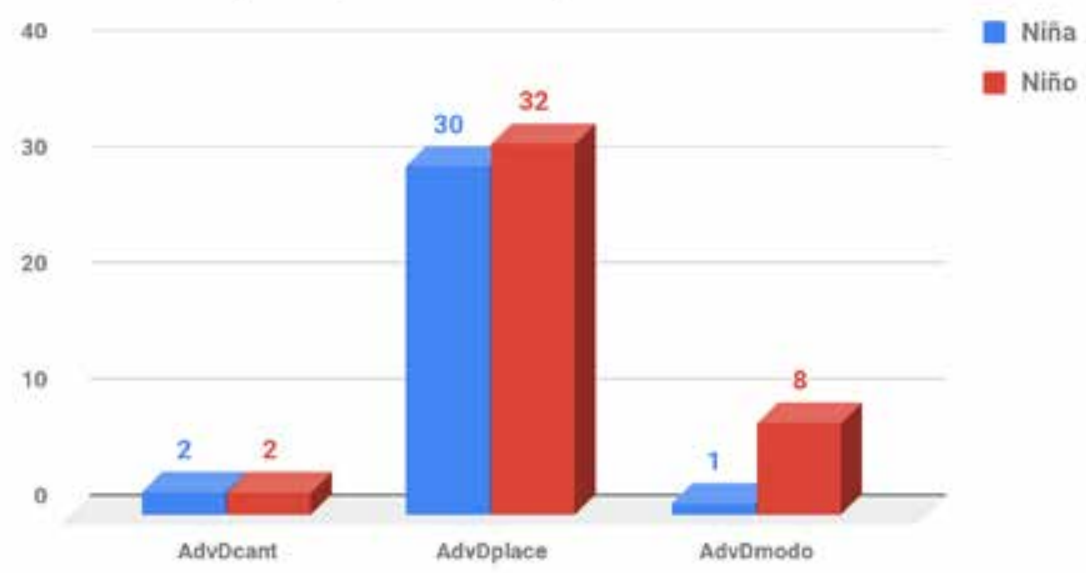

Gráfico 17: Adverbios en el Rompecabezas.

\section{Uso de nexos}

En el caso de la actividad de armar un rompecabezas se puede observar en la Gráfica No. 18 Nexos del Rompecabezas que los participantes tuvieron un mayor número de uso de nexos que en las anteriores dos actividades. El niño predominó en el uso de la mayoría de los nexos, aunque es importante recordar que el corpus del niño es más extenso que el de la niña. A continuación se darán ejemplos de cada ítem. 


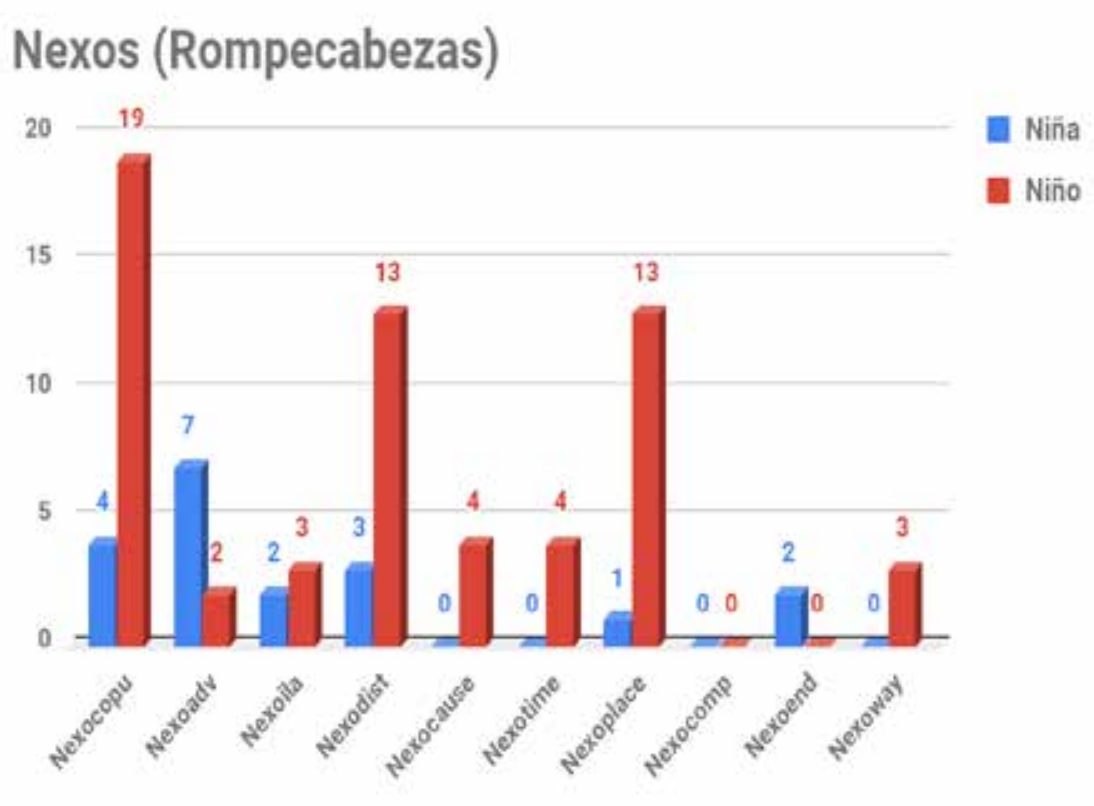

Gráfico 18: Nexos en el Rompecabezas.

A continuación se realizará el análisis de los resultados del último objetivo "solicitar información y solicitar ayuda si es necesario".

\section{Solicitar Información y/o Ayuda si es necesario}

La actividad de "el Rompecabezas" fue utilizada con el fin de visualizar a los participantes solicitando ayuda e información, ya que en las primeras actividades (Caja de Juguetes y Sigue la Historia) los menores no hicieron uso de frases u oraciones que nos permitieran analizar sus conocimientos en este objetivo. Por estos motivos se unieron los dos objetivos planteados por Gamazo (2016) "solicitar información si se requiere" y "solicitar ayuda si es necesario".

A continuación se mostrarán los resultados en la Gráfica 19, donde se puede observar la frecuencia de uso de cada ítem y posteriormente se ejemplifica.

\section{Solicitud de Ayuda (Rompecabezas)}

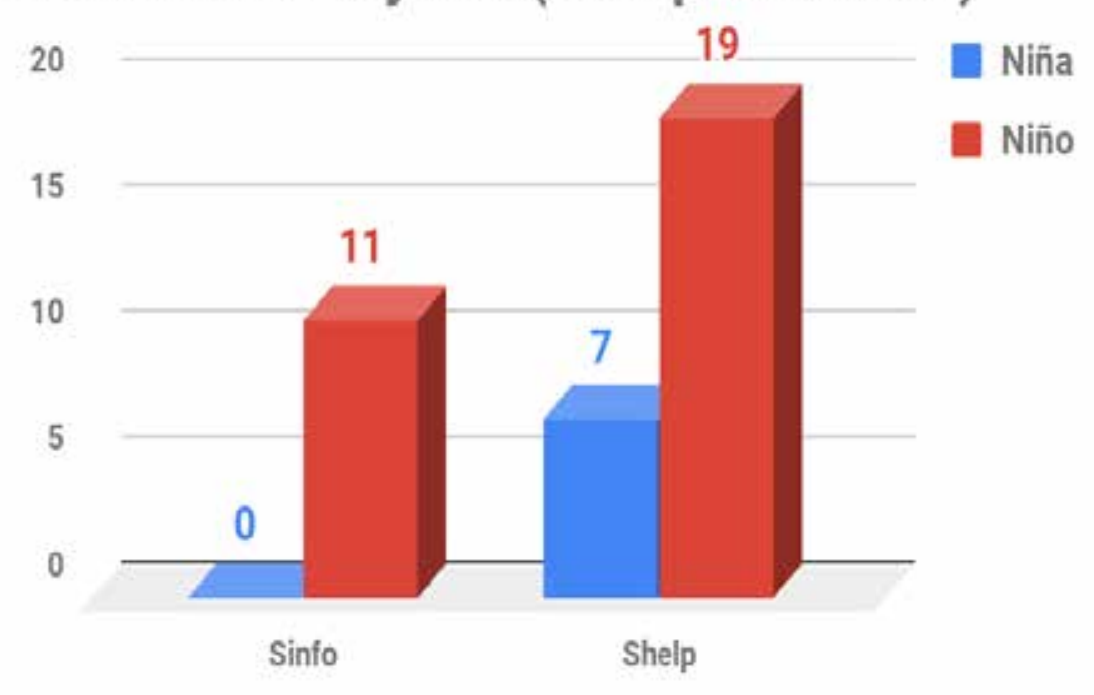

Gráfico 19: Solicitar información en el Rompecabezas.

El primer ítem corresponde a solicitar información si se requiere (Sinfo). En este caso es el niño quien mostró resultados. Esto se puede deber a que el menor no conocía los personajes que formaban el rompecabezas, mientras que el rompecabezas de la niña era de su personaje animado favorito.

El segundo ítem es sobre solicitar ayuda si es necesario (Shelp). En este caso ambos participantes mostraron resultados y como espe- rábamos con esta actividad, ambos niños se vieron en la necesidad de acudir a los adultos que los acompañaban para armar el rompecabezas.

Para concluir, la actividad "Rompecabezas" mostró resultados provechosos para la investigación. Ambos participantes utilizaron formas gramaticales diferentes y algunos con mayor frecuencia que en las primeras actividades. Adicionalmente, se lograron resultados en el último objetivo "solicitar información y/o ayuda si es necesario", el cual era el objetivo principal para esta actividad)

\section{Discusiones}

En consonancia con los resultados obtenidos por otros autores y teniendo en cuenta los objetivos de las actividades planteados en esta investigación, se ponen en discusión los resultados del presente estudio. El objetivo principal de esta discusión es proporcionar nueva evidencia empírica con respecto a la posible incidencia del género en el desarrollo de las habilidades conversacionales a la edad de los 3 años dentro de los niveles pragmáticos. A continuación, se realizará una discusión de cada uno de los resultados de los cinco objetivos.

Seguir el Tema de Conversación. En las tres actividades se evidenció que los participantes siguieron el tema de conversación de una manera continua, realizando aportes coherentes en cada actividad. Mostraron dominio del vocabulario y lo manejaron adecuadamente para cada conversación. En la primera actividad, "Caja de Juguetes”, ambos niños interactuaron coherentemente, describiendo y denominando los juguetes que se les presentaban. Se puede ver una diferencia con el hallazgo de Erikson et al. (2012), quienes en su investigación encontraron que las niñas tienen mayor vocabulario debido a los tipos de juguetes y juegos que realizan en su cotidianidad.

Adicionalmente, en este objetivo se encuentran similitudes con los resultados obtenidos por Borzone et al. (2011), quienes realizaron una investigación con dos niños de ambos sexos y demostraron un uso complejo, flexible y variado de los recursos lingüísticos para textualizar sus narraciones. Encontraron también que la influencia del contexto cognitivo incide en el proceso de textualización de ambos niños, ya que dependiendo del contexto los niños observados por ellos demostraron diferentes grados de dominios en relación con el cognitivo, es decir la relevancia que tiene el evento en la memoria del niño.

En este objetivo, Seguir el tema de conversación, se pudo evidenciar que los dos participantes de 3 años tienen la capacidad de realizar aportes al tema y cambiar el tópico de la conversación de manera espontánea, además de que siguen el tema de conversación durante toda la actividad. Estos resultados son congruentes con el planteamiento de Huamani (2014) en su tabla de Hitos del desarrollo de la pragmática, en donde argumenta que los niños entre los 36 y 48 meses de edad pueden dar continuidad al tema durante cinco turnos y pueden terminar adecuadamente la conversación. Respetar los turnos de palabra. En el caso de este objetivo se pudo evidenciar que ambos niños tienden a solapar el turno de los participantes de su edad, sin embargo, no hay evidencia de solapamiento en la conversación con adultos. En las actividades se observó que el niño tiende a solapar el turno de sus compañeros con mayor frecuencia y también se pudo evidenciar en este participante que reconoce cuando no es su turno en la conversación, pero está atento para que la actividad no pare y fluya de manera continua. Esto se observó y se utilizó en un ítem denominado AaT, "solapa el turno esperando un tiempo", puesto que en varias ocasiones el participante le daba a su compañera un tiempo prudente para que diera la respuesta o participara, pero al observar que no había una 
respuesta el niño participaba para que la conversación no sufriera un corte y se pudiera continuar con la actividad.

En comparación con otras investigaciones se pudo evidenciar semejanza con la investigación de Borzone et al. (2011), puesto que en sus resultados los autores argumentan que ambos participantes respetaron los turnos de manera general. Solo en ocasiones específicas no respetaron el turno, sobre todo en los momentos en que los investigadores realizaban intervenciones en las narraciones de los eventos que tenían mayor importancia para el participante. De esta manera, los niños no responden a la pregunta (el niño) o su respuesta es negativa (la niña) diciendo que no ha terminado su historia.

En este objetivo, Respetar los turnos de palabras, se pudo observar que los participantes tienen el conocimiento de la alternancia de turnos en una conversación; sin embargo, en ocasiones, tienden a solapar el turno. Esto concuerda con lo planteado en Huamani (2014) en su tabla de Hitos del desarrollo de la pragmática, donde manifiesta que los niños de esta edad "Anticipan el turno siguiente para hablar y Restauraciones de la toma de la palabra" (p.10), aclarando que en la presente investigación los participantes únicamente solapaban el turno de sus compañeros, es decir de los miembros de la conversación que tuvieran su misma edad.

Ser activo en la comunicación; se pudo observar que los dos participantes se mostraron activos en las tres actividades. También se pudo evidenciar la influencia del contexto social en la participación de los niños, puesto que cuando los niños estaban en su propia vivienda se sentían más cómodos para interactuar y exponer sus ideas. Fue en estos contextos donde ambos participantes tuvieron mayor interacción y donde expusieron sus ideas aportando al tema y cambiando el tópico de la conversación.

En comparación con otros estudios se encontraron similitudes con Borzone et al. (2011), quienes manifiestan que ambos participantes de su estudio son activos en sus narraciones y, en su caso, la actividad en la conversación es influenciada por el contexto cognitivo, más no por el contexto social, como en el caso de la presente investigación.

En este objetivo, Ser activo en la comunicación, se evidenció una participación continua y activa de ambos participantes. Esto resultado es semejante a los planteamientos presentados en la tabla de Hitos del desarrollo de la pragmática de Huamani (2014), donde se argumenta que los niños a esta edad participan en juegos de representación y empiezan a tener opinión. Estos dos conceptos van en la misma dirección de los resultados del presente trabajo investigativo, debido a que los niños después de los 36 meses pueden tener una participación activa y aportar con sus opiniones para mantener una conversación fluida y coherente.

Uso gramatical de las palabras; se observó claramente que ambos participantes tienen un dominio de varios pronombres, adverbios y nexos. Se evidenció además que los usaron de manera adecuada y pertinente en las conversaciones. Ambos niños usaron de manera espontánea pronombres tónicos (yo, él, ella), átonos (le, lo, la, las, me), demostrativos (ese, esa, este, está, esto), posesivos (mi) y preposicionales (para mí, a mi - niño-, de ella y a mí - niña-). Adicionalmente, en los adverbios, los participantes utilizaron únicamente adverbios de lugar (aquí, acá - ambos-; ahí, - niña-; arriba, - niño-), de cantidad (muy - ambos-; poco - niño-; más - niña-) y de modo (así, bien). Finalmente se observó que ambos niños utilizaron diversos tipos de nexos: copulativos (y), adversativos (pero), ilativos (también), distributivos (ya), causativos (porque), y de lugar (donde, a donde). Se observó en el uso de nexos que la niña utilizó el nexo final (para qué) y el nexo comparativo (como), mientras que el niño no lo utilizó en ninguna de las actividades. Por el contrario, se observó que el niño utilizó con mayor frecuencia el nexo de modo (como), el coordinante (uno y otro) y el de tiempo (primero y entonces).

En comparación con otros estudios, se observó que Pavez et al. (2010) encontraron que ambos sexos tienen emisión de elementos átonos pero que existe una constancia en el uso de las unidades tónicas en las palabras en los niños de sexo masculino. Esto se puede comparar con los resultados de la presente investigación en la que ambos participantes demostraron tener un dominio de los pronombres átonos y tónicos, con una muy leve y no significativa tendencia de mayor uso de todos los pronombres encontrados por parte de la niña.

Por otro lado, Borzone et al. (2011) encontraron en su investigación una diferencia en el uso de nexos dentro de las narraciones de sus participantes. Mientras que la niña utilizó nexos de tipo temporal (después), causal (porque), copulativo (y) y de adición (también), el niño utilizó los siguientes nexos: temporales (cuando), causales (porque), copulativos (y) y de lugar (ahí). Se observa una concordancia con nuestra investigación donde el niño también utilizó nexos de lugar, teniendo en cuenta que los niños de la investigación de estos autores tenían 5 años y que en la presente investigación se encontraron más hallazgos.

Solicitar información y/o ayuda si es necesario; se puede ver que para este objetivo ambos participantes solicitaron ayuda, siendo la niña más recurrente en cuanto a este tipo de solicitud. No obstante, en el momento de solicitar información, el cual fue el otro ítem analizado, el niño es quien mostró la necesidad de realizar preguntas relacionadas al tema, debido a que los personajes presentados en el rompecabezas eran totalmente desconocidos; a diferencia de la niña, quien sí tenía un previo y amplio conocimiento de los personajes.

Al comparar estos resultados con el estudio de Bonilla-Solórzano (2016) se encontró coherencia con los argumentos del autor, quien manifiesta que es a los 4 años aproximadamente cuando los niños se encuentran en un proceso de mejoría que les da la capacidad de narrar, describir y denominar una lámina, lo cual se manifestó en el desarrollo de esta actividad denominada "Rompecabezas". En esta actividad los niños demostraron la capacidad de describir y narrar lo que veían en las láminas del rompecabezas, construyendo así un diálogo espontáneo. De igual manera, podemos observar nuevamente los planteamientos desarrollados por Huamani (2014), quien explica que a partir de los 36 meses los niños comienzan a inferir información de fondo de las historias, lo cual estaría en concordancia con los resultados del análisis del ítem Solicitar información, en donde, por medio de imágenes, los participantes inferían la información y de esta manera sentían la necesidad de conocer más a fondo los personajes de los cuales trataba el rompecabezas. Así mismo, Huamaní (2014) argumenta que es aproximadamente a la edad de los 6 años que los niños empiezan a realizar consultas de tipo causal, y para este objetivo se evidenció cómo, desde más temprana edad, los niños pueden empezar a solicitar información específica.

\section{Conclusiones}

En concordancia con las observaciones realizadas en otros trabajos (Borzone et al. 2011, Erikson et al. 2012, Huamani 2014), los resultados del presente estudio proporcionan nueva evidencia con respecto al hecho de que el desempeño en la participación del niño y la niña durante una actividad puede variar dependiendo del contexto y de la cercanía con los interlocutores. Para el caso de esta investigación se evidenció la influencia del contexto social. 


\section{Desarrollo de la lengua materna: Incidencia del género con una visión pragmática}

Asimismo, los resultados permiten inferir que el solapamiento de turnos entre los participantes observados lo realizan con los participantes de su edad, sin embargo, no aparece solapamiento con los adultos. De igual manera y siguiendo a Borzone et al. (2011), para caracterizar el desempeño del componente pragmático en niños, se deben tener en cuenta no solo aspectos estructurales sino también la presencia de otros recursos tales como; el entorno social, la interacción, las preguntas oportunas, como el qué, cuándo, quién, etc., además del medio en el cual se está desarrollando el acto comunicativo.

Otra similitud importante, en comparación con otros estudios (Borzone et al. 2011, Erikson et al. 2012, Huamani 2014), fue el buen desempeño de ambos participantes en cada una de las actividades, realizando descripciones, definiciones, aportes a las conversaciones, solicitando información y ayuda y manteniendo los turnos de conversación de forma coherente durante toda la actividad. Esto permite evidenciar los hitos del desarrollo de la pragmática entre los 36 y 48 meses de edad.

En cuanto a la incidencia del género, y con base en los análisis aquí desarrollados, se observó que no hubo una diferencia significativa, lo cual lleva a deducir que no es el género el que incide en el desarrollo del componente pragmático en situaciones de habla espontánea. El hecho de que el niño y la niña hayan tenido un muy buen desempeño en las habilidades conversacionales durante cada una de las tres actividades realizadas muestra que ambos participantes tienen el mismo dominio y conocimiento al momento de una interacción espontánea dentro de un contexto social conocido.

\section{Referencias}

Acuña, X. y Sentis, F. (2004). Desarrollo pragmático en el habla infantil. Onomázein, 2(10), 33-56. Recuperado de: http://onomazein.letras. uc.cl/Articulos/10/2_Acuna.pdf

Alemán, N., Ardanaz, J., Echeverría, A., Poyo, D. y Yoldi, S. (2006). Evaluación de la comunicación y del lenguaje (ECOL).Centro de Recursos de Educación Especial de Navarra (CREENA) Gobierno de Navarra, Departamento de Educación.

Arconada, C. (2012). La adquisición del lenguaje en la etapa de 0 a 3 años. Universidad de Valladolid, Valladolid, España.

Arias-Gómez, J., Villasís-Keever, M. Á. y Novales, M. G. M. (2016). El protocolo de investigación III: la población de estudio. Revista Alergia México, 63(2), 201-206. Recuperado de: https:/www.redalyc.org/ pdf/4867/486755023011.pdf

Bertuccelli Papi, M. (1996), ¿Qué es pragmática?, Barcelona, Paidós.

Bonilla Solorzano, R. V. (2016). El desarrollo del lenguaje oral en niños de 4 años del colegio Hans Christian Andersen.

Borzone, A., Silva, M. y Plana, M. (2011). Habilidades discursivas y representaciones mentales. Lenguaje, 2011, 39 (2), 365-394. Recuperado de: http://www.scielo.org.co/pdf/leng/v39n2/v39n2a04. $p d f$

Botana, I., Peralbo, M. y García-Fernández, M. (2017). Indicadores tempranos de desarrollo pragmático y alteraciones del vínculo de apego Early Indicators of Pragmatic Development and Attachment Disorders. DOI: https://doi.org/10.17979/reipe.2017.0.09.2349

Carmona, M. B. (1985). Adquisición y evaluación de las funciones pragmáticas del lenguaje: un estudio evolutivo. Estudios de Psicología, 5(19-20), 35-49.

Coloma, C., Pavez, M., Maggiolo, M. y Peñaloza, C. (2010). Desarrollo fonológico en niños de 3 y 4 años según la fonología natural: Incidencia de la edad y del género. Revista Signos 2010, 43(72) 31-48. DOI: 10.4067/S0718-09342010000100002
Cotán Fernández, A. (2017). El sentido de la investigación cualitativa. Recuperado de: https://repositorioinstitucional.ceu.es/ bitstream/10637/8295/1/EA19-sentido.pdf

Crespo-Eguílaz, N., Magallón, S., Sánchez-Carpintero, R. y Narbona, J. (2016). La adaptación al castellano de la Children's Communication Checklist permite detectar las dificultades en el uso pragmático del lenguaje y diferenciar subtipos clínicos. https://doi.org/10.33588/ rn.62S01.2015526

Eriksson, M., Marschik, P. B., Tulviste, T., Almgren, M., Pérez Pereira, M., Wehberg, S. y Gallego, C. (2012). Differences between girls and boys in emerging language skills: Evidence from 10 language communities. British journal of developmental psychology, 30(2), 326-343.

Fernández Pérez, M. (2019). Eficacia comunicativa en el habla infantil. Indicadores pragmáticos básicos. Recuperado de: https://rodin.uca.es/bitstream/handle/10498/22065/ Pragmaling\%C3\%BC\%C3\%ADstica\%20N.27\%2032-53. pdf? sequence $=1 \&$ is Allowed $=y$

Gamazo, Y. R. (2016). Evaluación e intervención en el componente pragmático en niños de desarrollo típico (tesis de pregrado). Universidad de Valladolid, Valladolid, España.

Granato, L. y Rigatuso, E. M. (2020). Lenguaje e interacción verbal. ISBN 978987-655-222-6. Recuperado de:

http://repositoriodigital.uns.edu.ar/bitstream/123456789/4895/1/ Granato\%2C\%20L.\%20y\%20Rigatuso\%2C\%20E.\%20M.\%20 Lenguaje\%20e\%20interacci\%C3\%B3n\%20verbal.pdf

Huamanì, O. (2014). Desarrollo de las Habilidades Pragmáticas en la Infancia.Digital EOS Perù, 03(01), 19-26.

Lecompte, M. (1995). Un matrimonio conveniente: diseño de investigación cualitativa y estándares para la evaluación de programa. Revista Electrónica de Investigación y Evaluación Educativa.

López Suárez, A. (2019). Intersubjetividad Enactiva y Adquisición del Lenguaje en la Infancia. Recuperado de: https://repositorio. uahurtado.cl/bitstream/handle/11242/24546/MFMLCLopezS. pdf? sequence $=1 \&$ isAllowed $=y$

Otzen, T. y Manterola, C. (2017). Técnicas de Muestreo sobre una Población a Estudio. International journal of morphology, 35(1), 227-232. http:// dx.doi.org/10.4067/S0717-95022017000100037

Peralta Montecinos, J. (2000). Adquisición y desarrollo del lenguaje y la comunicación: una visión pragmática constructivista centrada en los contextos. Revista Interdisciplinaria de Filosofía y Psicología, (7) ,5466. ISSN: 0718-1361. Disponible en: https://www.redalyc.org/articulo. oa?id=836/83600704

Real Academia Española (RAE), (2011). Recuperado de: https://www.rae.es/ drae2001/contexto

Reyes, G. (2018). Palabras en contexto: pragmática y otras teorías del significado. Arco/Libros. Recuperado de: https://core.ac.uk/download/ pdf/322845285.pdf

Rodríguez Turriago, K. L. y Yepez Cuellar, E. A. (2017). La enseñanza de la lectura y la escritura a partir de vivencias y situaciones cotidianas como una estrategia pedagógica desde el enfoque pragmáticocontextual. Recuperado de: http://repositorio.unicauca.edu.co:8080/ xmlui/bitstream/handle/123456789/986/LA\%20ENSE\%C3\%91ANZA\%20 DE\%20LA\%20LECTURA\%20Y\%20LA\%20ESCRITURA\%20A\%20 PARTIR\%20DE\%2OVIVENCIAS\%20Y\%20SITUACIONES\%20COTIDIANAS. pdf? sequence=1\&isAllowed $=y$

Soncco, J. J. (2017). Lenguaje infantil y competencias socioemocionales en niños. Temática Psicológica, (13), 29-35. DOI: https://doi.org/10.33539/ tematpsicol.2017.v13n1.1303

Taylor, S.J. y Bogdan, R. (1986). Introducción a los métodos cualitativos de investigación. Editorial PAIDOS. Recuperado de: http://mastor.cl/blog/ wp-content/uploads/2011/12/Introduccion-a-metodos-cualitativos-deinvestigaci\%C3\%B3n-Taylor-y-Bogdan.-344-pags-pdf.pdf

Torres, M., Salazar, F. G. y Paz, K. (2019). Métodos de recolección de datos para una investigación. Recuperado de: http://biblioteca.udgvirtual. udg.mx/ispui/handle/123456789/2817 
Urbano Gómez P. A. (2016). Análisis de datos cualitativos. Fedumar Pedagogína Y Educación, 3(1). Recuperado de: http://editorial. umariana.edu.co/revistas/index.php/fedumar/article/view/1122

Varela Ospina, A., Varela Ospina, D. A. y Medina, V. H. (2017). Descripción de las categorías de la atenuación en artículos de investigación y sus traducciones desde un enfoque pragmático. Recuperado de: http:// repositorio.autonoma.edu.co/xmlui/bitstream/handle/11182/335/ Descripci\%C3\%B3n categor\%C3\%ADas atenuaci\%C3\%B3n art\%C3\%ADculos_investigaci\%C3\%B3n_traducciones_enfoque pragm\%C3\%Altico.pdf? sequence $=1$

Verde, S. (2015). El desarrollo de la competencia pragmática: aproximación al estudio del procesamiento pragmático del lenguaje. Universidad de Salamanca. Recuperado de: https://gredos.usal.es/bitstream/ handle/10366/128306/DLE VerdeRuizS Desarrollocompetencia.pdf. txt;jsessionid $=6620 \mathrm{A9361BAB8000786CD14DE6B1AA21 \text {?sequence } = 1 7}$ 